\title{
Morphine Withdrawal Enhances Constitutive $\mu$-Opioid Receptor Activity in the Ventral Tegmental Area
}

\author{
Frank J. Meye, ${ }^{1}$ Ruud van Zessen, ${ }^{1,2}$ Marten P. Smidt, ${ }^{1,3}$ Roger A.H. Adan, ${ }^{1}$ and Geert M. J. Ramakers ${ }^{1}$ \\ ${ }^{1}$ Rudolf Magnus Institute, Department of Neuroscience and Pharmacology, University Medical Center Utrecht, 3584 CG Utrecht, The Netherlands, \\ ${ }^{2}$ Master's Programme in Neuroscience and Cognition, Utrecht University, 3508 TC Utrecht, The Netherlands, and ${ }^{3}$ Swammerdam Institute of Life Sciences, \\ University of Amsterdam, 1090 GE Amsterdam, The Netherlands
}

$\mu$-Opioid receptors (MORs) in the ventral tegmental area (VTA) are pivotally involved in addictive behavior. While MORs are typically activated by opioids, they can also become constitutively active in the absence of any agonist. In the current study, we present evidence that MOR constitutive activity is highly relevant in the mouse VTA, as it regulates GABAergic input to dopamine neurons. Specifically, suppression of MOR constitutive activity with the inverse agonist KC-2-009 enhanced GABAergic neurotransmission onto VTA dopamine neurons. This inverse agonistic effect was fully blocked by the specific MOR neutral antagonist CTOP, which had no effect on GABAergic transmission itself. We next show that withdrawal from chronic morphine further increases the magnitude of inverse agonistic effects at the MOR, suggesting enhanced MOR constitutive activity. We demonstrate that this increase can be an adaptive response to the detrimental elevation in cAMP levels known to occur during morphine withdrawal. These findings offer important insights in the physiological occurrence and function of MOR constitutive activity, and have important implications for therapeutic strategies aimed at normalizing MOR signaling during addiction and opioid overdose.

\section{Introduction}

Endogenous opioids acting at the $\mu$-opioid receptor (MOR) serve a pivotal function in reward processing and addictive behaviors (Matthes et al., 1996; Hall et al., 2001; Olive et al., 2001; Ghozland et al., 2002; Mathon et al., 2003, 2005; Roth-Deri et al., 2003; Solinas et al., 2004; Jarjour et al., 2009; Mitchell et al., 2012). This is especially the case for MORs regulating the ventral tegmental area (VTA) (Bozarth and Wise, 1984; Wise, 1989; Laviolette et al., 2004), which typically suppress GABAergic inputs to VTA dopamine neurons (Johnson and North, 1992; Manzoni and Williams, 1999; Bergevin et al., 2002; Jalabert et al., 2011; Matsui and Williams, 2011).

Aside from activation by (endogenous) opioids, MORs can also exhibit constitutive signaling in the absence of any agonist (Burford et al., 2000; Wang et al., 2001; Sally et al., 2010). Constitutive MOR activity has been demonstrated in artificial cell systems (Wang et al., 1996, 2001; Burford et al., 2000; Liu and Prather, 2001; Liu et al., 2001; Sally et al., 2010), and in some

Received March 30, 2012; revised Aug. 31, 2012; accepted Sept. 9, 2012.

Author contributions: F.J.M., R.A.H.A., and G.M.J.R. designed research; F.J.M. and R.v.Z. performed research; M.P.S. contributed unpublished reagents/analytic tools; F.J.M. and R.v.Z. analyzed data; F.J.M., R.A.H.A., and G.M.J.R. wrote the paper.

We thank Top Institute Pharma (D1-105) for funding this project. Wealso thank Dr. Kenner Rice from the National Institutes of Health synthesis group for kindly supplying the compound KC-2-009. We thank Dr. Heidi M.B. Lesscher for helpful suggestions on the manuscript.

The authors declare no competing financial interests.

Correspondence should be addressed to Geert M.J. Ramakers, PhD, Rudolf Magnus Institute of Neuroscience, Department of Neuroscience and Pharmacology, UMC Utrecht, Universiteitsweg 100, 3584 CG Utrecht, The Netherlands. E-mail: g.m.j.ramakers@umcutrecht.nl.

DOI:10.1523/JNEUROSCI.1572-12.2012

Copyright $\odot 2012$ the authors $\quad 0270-6474 / 12 / 3216120-09 \$ 15.00 / 0$ native tissues (Wang et al., 2004; Heinzen et al., 2005; Raehal et al., 2005; Walwyn et al., 2007). Intriguingly, there is evidence that reduction of constitutive MOR activity exacerbates the expression of physical and psychological opioid withdrawal symptoms (Wang et al., 1994; Bilsky et al., 1996; Raehal et al., 2005; Shoblock and Maidment, 2006; Lam et al., 2011). Part of the neuroanatomical substrate for such adverse effects is likely a hypofunctional mesolimbic dopamine system (Acquas et al., 1991; Diana et al., 1995, 1999; Koob and Le Moal, 1997, 2001; Aston-Jones and Harris, 2004; Radke et al., 2011). Reduced dopamine signaling during morphine withdrawal can arise due to increased GABAergic signaling onto VTA dopamine neurons (Bagley et al., 2011). This enhancement of inhibitory signals has been reported to occur as a consequence of morphine withdrawal-induced elevations in cAMP (cAMP superactivation) in GABAergic terminals (Bonci and Williams, 1997; Madhavan et al., 2010a). Together, these findings point to an important role of GABAergic signaling onto VTA dopamine neurons in the occurrence of opiate withdrawal symptoms.

Currently, separate lines of evidence implicate the VTA on the one hand, and constitutively active MORs in general on the other hand, in the process of opiate withdrawal. However, no converging findings have shown a role for MOR constitutive activity in the regulation of the VTA during opiate withdrawal. Furthermore, the actual physiological relevance of MOR constitutive activity, be it in an opiate-naive or an opiate-experienced state, remains poorly understood. In the current study we provide evidence that MOR constitutive activity already controls the GABAergic inputs of VTA dopamine neurons during a drugnaive state, and exerts even more prominent control during morphine withdrawal. 


\section{Materials and Methods}

Animals. All experiments were approved by the Animal Ethics Committee of Utrecht University and were conducted in agreement with Dutch law (Wet op de Dierproeven, 1996) and European regulations (Guideline 86/609/EEC). Electrophysiological experiments were performed in heterozygous Pitx3-GFP mice [ $n=90$, postnatal day 14-30] of either sex. These mice were obtained by crossing C57BL6-Jico wild-type with Pitx $3^{\text {gfp/gfp }}$ mice. These animals have selective GFP expression in dopaminergic neurons in the midbrain, allowing for their accurate identification (Smidt et al., 1997; Zhao et al., 2004; Labouèbe et al., 2007; Mameli et al., 2009; Padgett et al., 2012).

For morphine withdrawal experiments, mice were treated twice daily with morphine ( $10 \mathrm{mg} / \mathrm{kg}$ ) (or saline for controls) for 5 consecutive days. This protocol has been demonstrated to induce morphine dependence (Madhavan et al., 2010a,b). This regimen was followed by 3-4 d of morphine abstinence, after which animals were killed for electrophysiological experiments.

Electrophysiology. Electrophysiological experiments were conducted as described earlier (Mathon et al., 2005; de Rover et al., 2008). Animals were anesthetized with isoflurane and then decapitated. Subsequently, the brain was rapidly removed and stored in ice-cold carbogenated (95\% $\mathrm{O}_{2} / 5 \% \mathrm{CO}_{2}$ ) enriched artificial CSF (ACSF), consisting of the following (in mM): $124 \mathrm{NaCl}, 3.3 \mathrm{KCl}, 1.2 \mathrm{KH}_{2} \mathrm{PO}_{4}, 2.5 \mathrm{CaCl}_{2}, 2.6 \mathrm{MgSO}_{4}, 20$ $\mathrm{NaHCO}_{3}, 10$ glucose, and 1 ascorbic acid. Horizontal brain slices of 200 $\mu \mathrm{m}$ were cut in the same chilled medium on a Vibratome (Leica). After cutting, slices were incubated in carbogenated normal ACSF (final $\mathrm{MgSO}_{4}$ concentration of $1.3 \mathrm{~mm}$, no ascorbic acid). Slices were left to recover for $1 \mathrm{~h}$ at $32^{\circ} \mathrm{C}$. During recordings, a slice was mechanically stabilized and continuously superfused with carbogenated normal ACSF at a rate of $2-3 \mathrm{ml} / \mathrm{min}$ at room temperature.

Dopaminergic VTA neurons were identified as green fluorescent neurons within an anatomically circumscribed region consisting of the area rostral to the medial lemniscus, medial to the medial terminal nucleus of the accessory optical tract, and lateral of the interpeduncular fossa. In these neurons, whole-cell voltage-clamp recordings were obtained with an EPC-10 patch-clamp amplifier, using Patchmaster v2x32 software (HEKA Electronics). Recordings were made using borosilicate glass pipettes filled with the following (in $\mathrm{mm}$ ): $78 \mathrm{~K}$-gluconate, $77 \mathrm{KCl}, 10$ HEPES, 1 EGTA, $2 \mathrm{Mg}^{2+}$-ATP, $0.4 \mathrm{Na}^{+}$-GTP, pH 7.4, which yielded a pipette resistance of 3-5 M $\Omega$. Data were sampled at $20 \mathrm{kHz}$. Immediately after patching, cells were voltage-clamped at $-60 \mathrm{mV}$ and allowed to recover for at least $10 \mathrm{~min}$ before baseline recordings. Miniature IPSCs (mIPSCs) were recorded in the presence of $1 \mu \mathrm{M}$ TTX and $10 \mu \mathrm{M}$ DNQX. To ensure stable recordings, cells were discarded when the product of uncompensated series resistance and cell capacitance varied too strongly over time ( $>20 \%$ change).

For all recorded cells, the membrane capacitance was calculated in Patchmaster v2x32 software (HEKA Electronics), using a rectangular test pulse $(5 \mathrm{mV}, 5 \mathrm{~ms})$ to evoke transient capacitance currents. H-currents for cells were determined by a protocol where neurons were clamped for $2 \mathrm{~s}$ to incrementally ( $-10 \mathrm{mV}$ increment) greater hyperpolarizing values spanning from -70 to $-120 \mathrm{mV}$. The maximal evoked current at -120 $\mathrm{mV}$ was taken as the value of the h-current (Mathon et al., 2005; de Rover et al., 2008).

For analysis, events were scored using MiniAnalysis software (Synaptosoft) and distributions of frequency and amplitude were fitted in Igor Pro (Wavemetrics) with a lognormal curve: $\mathrm{f}(x)=A^{*} \exp [-0.5 *(\ln$ $\left.X-\mu) / \sigma)^{2}\right] /\left(x^{*} \sigma^{*} \sqrt{ } 2 \pi\right)$, as described previously (Brussaard et al., 1996; de Rover et al., 2008). In this equation $x$ represents the measured instantaneous frequency or amplitude of an event, $A$ is the relative area under the curve of the distribution, $\mu$ is the mean, and $\sigma$ the SD of the underlying normal distribution. The mean of the lognormal distribution $(m)$ was then calculated using the equation: $m=\exp \left(\mu+\sigma^{2}\right)$ to allow for the determination of percentage-wise changes. For the calculation of mIPSC kinetics, the decay time to $50 \%$ of the peak value for every mIPSC was calculated in MiniAnalysis (Synaptosoft). To assess drug effects, twotailed repeated measures or one-way ANOVAs were performed on the means of the normally distributed data. The Mann-Whitney $U$ test was performed in the case of nonparametric tests. All statistical analyses were done in SPSS 17.0.

Drugs. The AMPA/kainate receptor antagonist DNQX, the voltagegated $\mathrm{Na}^{+}$-channel blocker TTX, the MOR agonist DAMGO, and the MOR neutral antagonist D-Phe-Cys-Tyr-D-Trp-Orn-Thr-Pen-Thr- $\mathrm{NH}_{2}$ (CTOP) were from Tocris Bioscience. Forskolin (FSK) was from SigmaAldrich. Morphine-HCl was from Mediq. The MOR inverse agonist KC2-009 was a kind gift from Dr. Kenneth Rice at the NIH synthesis program.

\section{Results}

\section{Inverse agonistic effects at MORs on GABAergic projections} to VTA dopamine neurons

To determine the contribution of MOR constitutive activity in the VTA, we first determined the effect of MOR activation itself. MOR agonists have been reported to hyperpolarize VTA GABA neurons (Johnson and North, 1992) and to reduce their release probability (Bergevin et al., 2002). We patch-clamped Pitx3GFP-positive VTA dopamine neurons and isolated GABAergic mIPSCs in the presence of TTX $(1 \mu \mathrm{M})$ and DNQX $(10 \mu \mathrm{M})$. As expected, administration of the MOR agonist DAMGO $(1 \mu \mathrm{M})$ reduced the GABAergic mIPSC frequency to $55.15 \pm 5.40 \%$ of baseline $\left(n=14, F_{(1,13)}=28.34, p<0.001\right.$, repeated-measures ANOVA; Fig. $1 A, B)$. DAMGO did not affect the amplitude of $\operatorname{mIPSCs}\left(F_{(1,13)}=0.12, p=0.73\right.$, repeated-measures ANOVA; Fig. $1 B, C)$, in accordance with reports that MORs are located presynaptically on GABAergic nerve terminals in the VTA (Garzon and Pickel, 2001). DAMGO exerted its effect on frequency at various doses $\left(F_{(1,23)}=47.00, p<0.001\right.$, repeated-measures ANOVA; Fig. $1 C)$. In wild-type mice, DAMGO $(1 \mu \mathrm{M})$ reduced mIPSC frequency to a comparable extent $(56.94 \pm 9.53 \%$ of baseline, $n=5, F_{(1,4)}=20.41, p<0.05$, repeated-measures ANOVA, data not shown), indicating a normal MOR system in the Pitx3GFP heterozygous animals.

Activation of MORs decreases inhibitory signals onto VTA dopamine neurons. If some of these MORs are already constitutively active, the suppression of their constitutive activity would increase inhibitory signals onto VTA dopamine neurons. We administered the MOR inverse agonist KC-2-009 (1 $\mu \mathrm{M}$ ) (Sally et al., 2010) to suppress constitutive MOR activity and indeed observed a clear increase in mIPSC frequency to $143.70 \pm 9.77 \%$ of baseline $\left(n=5, F_{(1,4)}=41.91, p<0.01\right.$, repeated-measures ANOVA; Fig. 2A,B). The effect of KC-2-009 on mIPSC frequency was without a concomitant effect on amplitude $\left(F_{(1,4)}=\right.$ $0.04, p=0.85$, repeated-measures ANOVA; Fig. $2 B, C)$, similarly in line with a presynaptic locus of action. The effect of KC-2-009 on mIPSC frequency was clear at various concentrations $\left(F_{(1,13)}\right.$ $=144.59, p<0.001$, repeated-measures ANOVA; Fig. $2 C)$. The absence of dose dependence over this range indicated that the maximal effect of KC-2-009 was already obtained at $100 \mathrm{nM}$ $\left(F_{(2,13)}=0.17, p=0.85\right.$, repeated-measures ANOVA treatmentdose, Fig. 2C).

Alternative explanations for the inverse agonistic effect of $\mathrm{KC}$ 2-009 other than suppression of MOR constitutive activity are (1) interference with endogenous opioids acting at the MOR, (2) a MOR-independent effect, or (3) a specific effect on a subset of MORs with different downstream coupling. To investigate these alternative possibilities, we tested the MOR-specific neutral antagonist CTOP, which is also fully capable of blocking MOR activation by endogenous opioids (Wang et al., 1994). CTOP (1 $\mu \mathrm{M})$ by itself affected neither mIPSC frequency $\left(n=9, F_{(1,8)}=\right.$ $0.08, p=0.79$; Fig. $3 A, B)$ nor amplitude $\left(F_{(1,8)}=0.85, p=0.38\right.$, repeated-measures ANOVAs; Fig. $3 B, C)$ compared with base- 
line. The lack of a direct effect of CTOP on GABAergic transmission was not due to insufficient MOR occupation. At a higher concentration, CTOP $(5 \mu \mathrm{M})$ did not affect mIPSC frequency either $\left(n=5, F_{(1,4)}\right.$ $=0.05, p=0.83$, repeated-measures ANOVA; Fig. 3C). Moreover, preadministration of either 1 or $5 \mu \mathrm{M}$ CTOP blocked the effect of subsequently administered $\mathrm{KC}-2-009(1 \mu \mathrm{M})\left(F_{(1,9)}=0.04\right.$, $p=0.85$, repeated-measures ANOVA; Fig. 3C). Likewise, the effect of the MOR agonist DAMGO $(1 \mu \mathrm{M})$ was blocked by preadministration of the neutral MOR antagonist CTOP $(1 \mu \mathrm{M})\left(n=8, F_{(1,7)}=\right.$ 1.55, $p=0.25$, repeated-measures ANOVA; Fig. 3C). It has been reported that KC-2-009 also has low affinity for the $\kappa$-opioid receptor (KOR) (Sally et al., 2010). While the efficacy of KC-2-009 in our assay suggested a MOR-dependent effect, we still tested whether the effect of KC-2-009 was indeed not mediated by the KOR. In the presence of the KOR antagonist nor-binaltorphimine (Nor-BNI; 10 $\mathrm{nM}$ ), at a dose that should block KORdependent effects, but not MORdependent effects (Takemori et al., 1988), KC-2-009 (1 $\mu \mathrm{M})$ still clearly increased mIPSC frequency to $149.87 \pm 19.45 \%$ of baseline $\left(n=4 ; F_{(1,3)}=17.91, p<0.05\right.$, repeated-measures ANOVA; Fig. $3 C$ ).

These findings indicate that the effect of KC-2-009 is both MOR dependent and not due to interference with signaling of endogenously present opioids acting at the MOR in our slice preparation. One unexplored hypothetical situation would be that KC-2-009 had specific effects on a subset of MORs different from those affected by DAMGO (e.g., different MOR isoforms), with these MORs potentially having alternate downstream signaling properties (Cadet et al., 2003). In this particular scenario, DAMGO and KC-2-009 would have different loci of effect (i.e., different MOR subsets). To test this possibility, we preadministered $\mathrm{KC}-2-009(1 \mu \mathrm{M})$, let its enhancing effect on mIPSC frequency stabilize, and then administered DAMGO $(1 \mu \mathrm{M})$. If DAMGO would affect a different subset of MORs than KC-2-009, it would not compete with $\mathrm{KC}-2-009$ for binding, permitting its inhibiting effect to occur in the presence of a stabilized KC-2-009 effect. Instead, we observed that the effect of DAMGO was blocked by preadministered KC-2-009 $\left(n=4, F_{(1,3)}=0.36, p=\right.$ 0.59 , repeated-measures ANOVA; Fig. $3 C$ ). This finding is indicative of a similar locus of effect (i.e., similar MORs) of both DAMGO and KC-2-009.

We also investigated whether there were indications that the neurons from DAMGO and KC-2-009 experiments had inadvertently been sampled from distinct VTA dopamine neuron subpopulations. Such subpopulations can have distinct anatomical connections (Fields et al., 2007), potentially innervated by separate GABAergic afferents subject to differential MOR con${ }^{* *} p<0.01 ;{ }^{* * *} p<0.001$.
Baseline

DAMGO

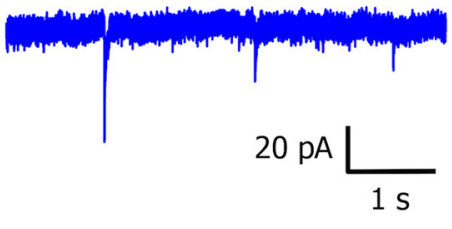

- Baseline

- DAMGO
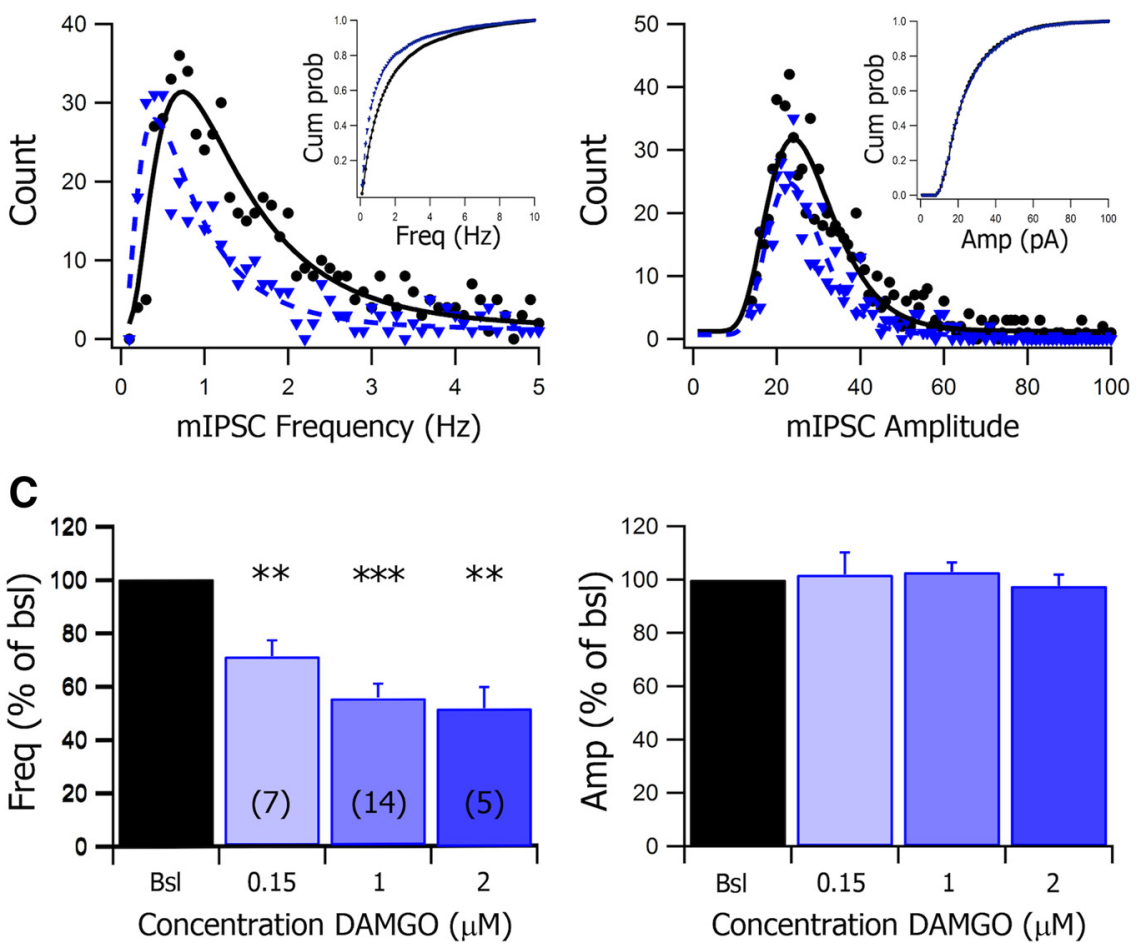

Figure 1. The MOR agonist DAMGO suppresses mIPSC frequency onto VTA dopamine neurons. $A$, Example traces of mIPSCs in the absence (black) and presence (blue) of $1 \mu \mathrm{m}$ DAMGO. mIPSC frequency is diminished after administration of the MOR agonist. treatment as percentage of baseline, with the number of experiments in parentheses. DAMGO reduces mIPSCs across various doses.

trol. Important markers for VTA subpopulations are h-current and cell size (Neuhoff et al., 2002). We found no difference in cell capacitance between neurons from DAMGO and KC-2-009 experiments (DAMGO: $18.11 \pm 3.05$ pF; KC2-009: $19.57 \pm 2.53 \mathrm{pF}, F<1$, one-way ANOVA), which is an index for cell size, or on h-current (DAMGO cells: $175.00 \pm 78.77$ pA; KC-2-009 cells: $101.82 \pm 40.38$ pA, $F<1$, one-way ANOVA). Neither did we observe differences in MIPSC basal input frequency (DAMGO cells: $1.93 \pm 0.23 \mathrm{~Hz}$; KC-2-009 cells: $1.67 \pm$ $0.33 \mathrm{~Hz}, F<1$, one-way ANOVA), or in mIPSC decay time kinetics (pre-DAMGO: $2.13 \pm 0.16 \mathrm{~ms}$; post-DAMGO: $2.20 \pm$ 0.18 ms; pre-KC-2-009: $2.00 \pm 0.09 \mathrm{~ms}$; post-KC-2-009: $2.01 \pm$ $0.06 \mathrm{~ms} ; F<1$ for main effects and drug-treatment interaction, repeated-measures ANOVA). These findings suggest that the a priori selection of cells in these two experimental groups had not been biased. Overall, the inverse agonistic effect of KC-2-009 is therefore 


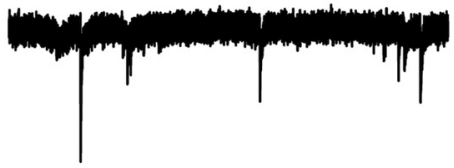

B - Baseline
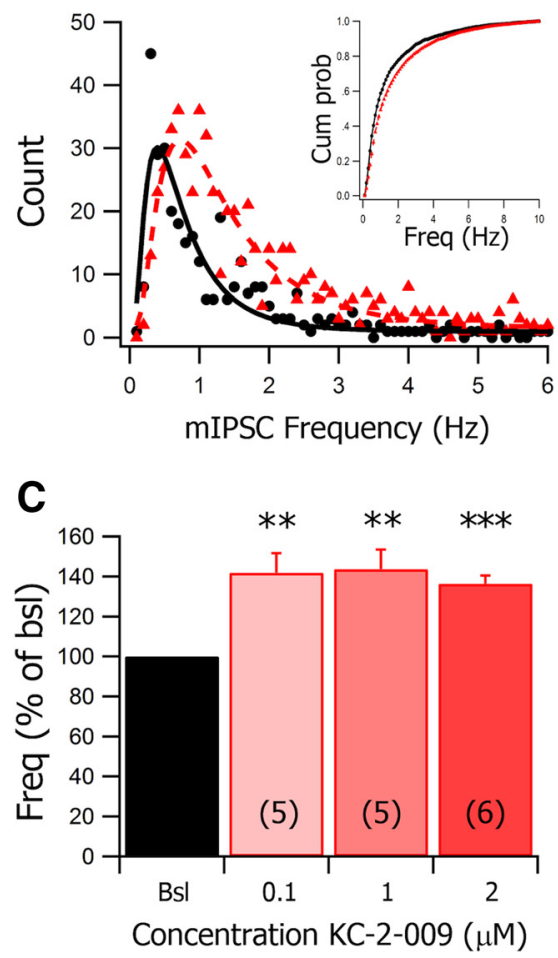

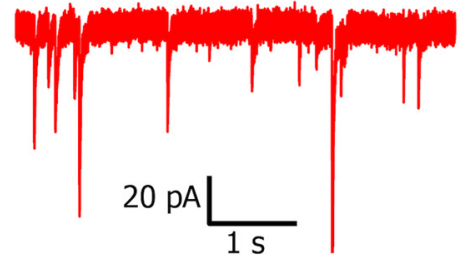

KC-2-00-9
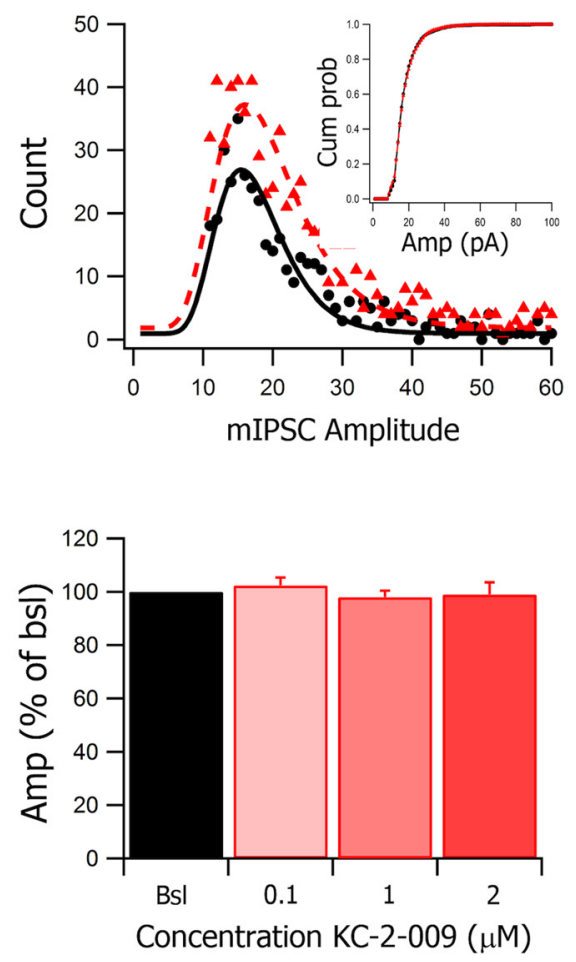

Figure 2. The MOR inverse agonist KC-2-009 enhances mIPSC frequency onto VTA dopamine neurons. $A$, Representative traces of $\mathrm{mIPSC}$ in the absence (black) and presence (red) of $1 \mu \mathrm{M} \mathrm{KC}-2-009$. Administration of this MOR inverse agonist increases mIPSC frequency. $\boldsymbol{B}$, Exemplar lognormal distributions of mIPSC acute frequency (left) and amplitude (right) during baseline (black circles) and after administration of $1 \mu \mathrm{m} \mathrm{KC-2-009}$ (red triangles). The MOR inverse agonist induces a rightward shift in the mIPSC frequency distribution, indicating a higher frequency of GABA transmission. Inset, Cumulative probability plot of mIPSC frequency (left) and amplitude (right) of all experiments before (black circles) and after $1 \mu \mathrm{M} \mathrm{KC}-2-009$ (red triangles). C, Average acute frequency (left) and amplitude (right) as a percentage of baseline after various doses of KC-2-009. KC-2-009 clearly increased mIPSC frequency at all these doses. The number of experiments per dose is indicated in parentheses. ${ }^{* *} p<0.01$; ${ }^{* *} p<0.001$.

best explained by suppression of the constitutive activity that MORs on GABAergic afferents to VTA dopamine neurons exhibit.

\section{Withdrawal from chronic morphine enhances inverse agonistic effects at the MOR}

During morphine withdrawal, MOR inverse agonists evoke stronger withdrawal symptoms (e.g., withdrawal jumping, paw tremors, and conditioned place aversion) than MOR neutral antagonists (Wang et al., 1994; Bilsky et al., 1996; Raehal et al., 2005; Shoblock and Maidment, 2006). This suggests that MOR constitutive activity becomes more important during morphine withdrawal, especially in regions involved in the expression of withdrawal symptoms, like the VTA (Baumeister et al., 1989; Koob and Le Moal, 1997, 2001; AstonJones and Harris, 2004; Radke et al., 2011). Therefore, we investigated whether the constitutive MOR activity in the VTA would be enhanced during morphine withdrawal.

We pretreated mice with morphine ( $10 \mathrm{mg} / \mathrm{kg}$ twice daily) for $5 \mathrm{~d}$ to induce opiate dependence (Madhavan et al., 2010a,b), followed by 3-4 $\mathrm{d}$ of abstinence to examine withdrawal. A characteristic feature of morphine withdrawal is an increase in GABAergic activity in regions like the VTA (Bagley et al., 2011), leading to enhanced GABAergic neurotransmission onto VTA dopamine neurons (Bonci and Williams, 1997; Madhavan et al., 2010a), associated with detrimental opiate withdrawal symptoms (Madhavan et al., 2010a). Accordingly, we observed that withdrawal from chronic morphine pretreatment $(n=15)$ increased the frequency of mIPSCs onto VTA dopamine neurons by $66.08 \%\left(F_{(1,48)}=4.09, p<\right.$ 0.05 , one-way ANOVA; Fig. $4 A)$, compared with control [saline pretreated $(n=6)$ pooled with untreated controls $(n=29)$, which were statistically similar, $F_{(1,33)}=$ $0.21, p=0.65$, one-way ANOVA]. We did not observe an effect of pretreatment on mIPSC amplitude $\left(F_{(1,48)}=1.73, p=0.20\right.$, one-way ANOVA, data not shown).

If MOR constitutive activity is indeed enhanced in the VTA during morphine withdrawal, the inverse agonistic effect of KC-2-009 should be enhanced. We compared the effect of MOR inverse agonist KC-2-009 (compared with the cell's own baseline, to control for any effects of morphine pretreatment on input frequency itself) after three conditions: (1) 3 or $4 \mathrm{~d}$ after chronic saline treatment, (2) a short $12 \mathrm{~h}$ abstinence after chronic morphine treatment, and (3) 3 or $4 \mathrm{~d}$ of abstinence after chronic morphine treatment. We observed a main effect of KC-2-009 (1 $\mu \mathrm{M})$ on mIPSC frequency $\left(F_{(1,13)}=32.13\right.$, $p<0.001$, repeated-measures ANOVA; Figure $4 B$ ). Importantly, the effect of KC2-009 was stronger after 3-4 d of morphine withdrawal (baseline: $1.79 \pm 0.45$ $\mathrm{Hz}$; KC-2-009: $5.15 \pm 1.30 \mathrm{~Hz}$ ) than in the other conditions (saline: saline baseline, $1.58 \mathrm{~Hz} \pm 2.09 \mathrm{~Hz}$; KC-2-009, $2.09 \pm 0.57$ $\mathrm{Hz}$; morphine: morphine $12 \mathrm{~h}$ baseline, $1.64 \pm 0.85 \mathrm{~Hz}$; KC-2-009: $1.85 \pm 1.00 \mathrm{~Hz})$, as revealed by a significant pretreatment-acute drug effect interaction $\left(F_{(2,13)}=\right.$ 10.46, $p<0.01$, repeated-measures ANOVA; Figure $4 B$ ).

The increased effect of the MOR inverse agonist KC-2-009 is in accordance with enhanced MOR constitutive signaling. However, the increased effect could also have been due to interference with endogenous opioids potentially released during morphine withdrawal. To examine this possibility, we tested the effect of the MOR neutral antagonist CTOP after 3-4 d of morphine withdrawal. Under these conditions CTOP still did not affect mIPSC frequency $\left(n=5, F_{(1,4)}=0.02, p=0.90\right.$, repeated-measures ANOVA; Fig. $4 B$ ), indicating that the enhanced effect of $\mathrm{KC}-2$ 009 could not be explained by a withdrawal-induced increase in endogenous opioids in our slice preparation.

The enhanced inverse agonistic effect of KC-2-009 during withdrawal could be due to a general increase in MOR density, raising the amount of both constitutively active and inactive MORs in absolute terms in a similar ratio. In this scenario, a MOR agonist would also 
be predicted to have an increased effect. Alternatively, morphine withdrawal could lead to a shift from inactive to constitutively active MORs, in which case a MOR agonist would be predicted to have a diminished effect. In agreement with this second scenario, DAMGO ( $1 \mu \mathrm{M} ; n=6)$ only suppressed GABAergic input $(\geq 20 \%)$ in a minority of dopaminergic neurons ( 2 of 6 cells) after morphine pretreatment, which differed significantly from the vast majority of dopaminergic neurons disinhibited by an equimolar concentration of DAMGO in a drug-naive state (13 of 14 cells; Mann-Whitney $U$ test, $p<0.05$; Fig. 4C).

\section{Enhancement of cAMP levels increases} inverse agonistic effects at the MOR

The withdrawal symptoms after chronic morphine treatment are caused by adaptive changes such as the upregulation of the cAMP-dependent cascade (Sharma et al., 1975). In the VTA, such cAMP superactivation has been reported to increase GABAergic input to VTA dopamine neurons (Bonci and Williams, 1997), and is responsible for negative withdrawal symptoms (Madhavan et al., 2010a). Enhanced MOR constitutive activity could be an adaptive countermeasure to partly suppress the withdrawal-induced cAMP overshoot and concomitant enhanced GABAergic transmission in the VTA. Therefore, we tested whether activation of the cAMP cascade was sufficient to enhance MOR constitutive activity. We treated slices of drug-naive animals with FSK to mimic the cAMP superactivation component of the morphine withdrawal state. Compared with control $(n=29)$, FSK treatment (100 nM; $n=18$ ) evoked an increase in the frequency of mIPSCs to $231.78 \%\left(F_{(1,45)}=17.97, p<0.001\right.$, oneway ANOVA; Fig. 5A), just like actual morphine withdrawal. We did not observe a significant effect of FSK treatment on mIPSC amplitude $\left(F_{(1,45)}=1.15, p=\right.$ 0.29 , one-way ANOVA; Fig. $5 A$ ). In these experiments, slices were incubated with FSK for at least $40 \mathrm{~min}$ to obtain a stable effect, which then served as a new baseline for subsequent drug administration. KC2-009 (1 $\mu \mathrm{M})$ enhanced mIPSC frequency overall $\left(F_{(1,10)}=31.71, p<0.001\right.$, repeated-measures ANOVA, main effect).

However, compared with control $(n=6$, KC-effect: $133.98 \pm$ $12.58 \%$ of baseline), pretreatment with FSK led to an increased effect of KC-2-009 on mIPSC frequency $(n=6$, KC-effect: $190.78 \pm 24.17 \%$ of the stabilized FSK-containing baseline), as indicated by a significant pretreatment-acute drug effect interaction $\left(F_{(1,10)}=6.32, p<0.05\right.$, repeated-measures ANOVA; Fig. $5 B)$. Again, no effects on amplitude were observed $(F<1$ for main effects or interaction, data not shown). Acute administra-

B

CTOP

DAMGO

KC

Nor-BNI
Baseline
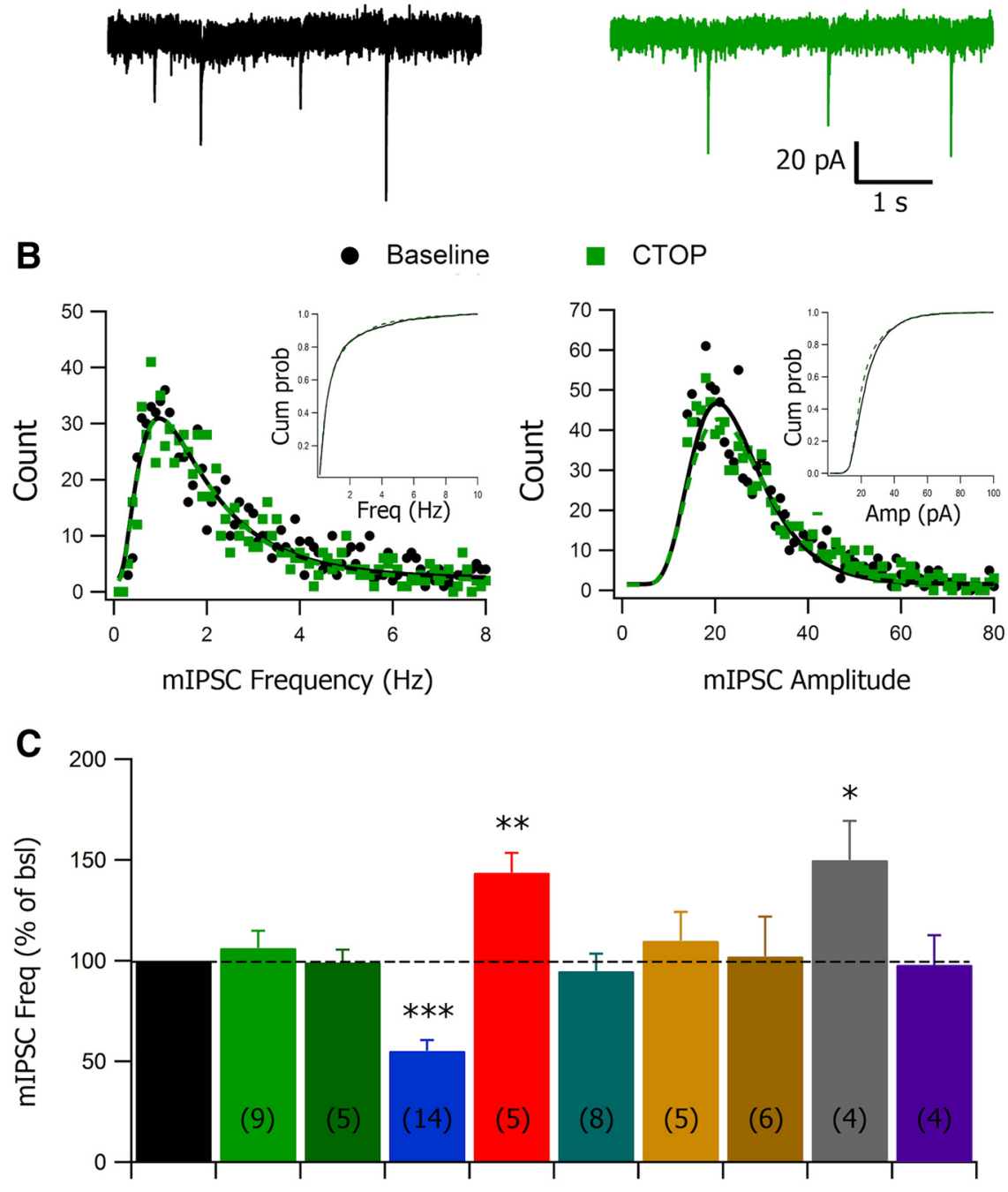

1

5

-

$-$

$-\quad-\quad$

1

(1)

Figure 3. The inverse agonistic effect of KC-2-009 is due to suppression of MOR constitutive activity. $A$, Representative traces of $\mathrm{mIPSC}$ in the absence (black) and presence (red) of $1 \mu \mathrm{m}$ the MOR neutral antagonist CTOP, which did not affect mIPSC frequency or amplitude. $\boldsymbol{B}$, Associated exemplar lognormal distributions of mIPSC acute frequency (left) and amplitude (right) during baseline (black circles) and after administration of $1 \mu \mathrm{M}$ (TOP (green squares). CTOP did not change the mIPSC frequency or amplitude distributions. Insets, Cumulative probability plots for mIPSC frequency (left) and amplitude (right) of all experiments before (black circles) and after $1 \mu \mathrm{m}$ CTOP (green squares). C, Overview of the effect of various MOR ligands on mIPSC frequency in the VTA, with the number of experiments indicated in parentheses. Whereas the neutral antagonist CTOP did not affect mIPSCs itself, it did block the effects of both DAMGO and KC-2-009. In contrast, the KOR antagonist Nor-BNI could not block the effect of KC-2-009. Pretreatment with KC-2-009 also prevented the effect of DAMG0. ${ }^{*} p<0.05$; ${ }^{* *} p<0.01 ;{ }^{* * *} p<0.001$.

tion of the neutral antagonist CTOP after FSK treatment $(n=4)$ or control $(n=9)$ did not increase mIPSC frequency $(F<1$ for main effect of CTOP or interaction with FSK pretreatment, repeated-measures ANOVA; Fig. 5B). Therefore, the enhanced effect of KC-2-009 was not due to either FSK-induced release of endogenous opioids or an ongoing effect of FSK itself. Instead, these data indicate that when the cAMP cascade is activated, GABAergic inputs onto VTA dopamine neurons are enhanced, as 

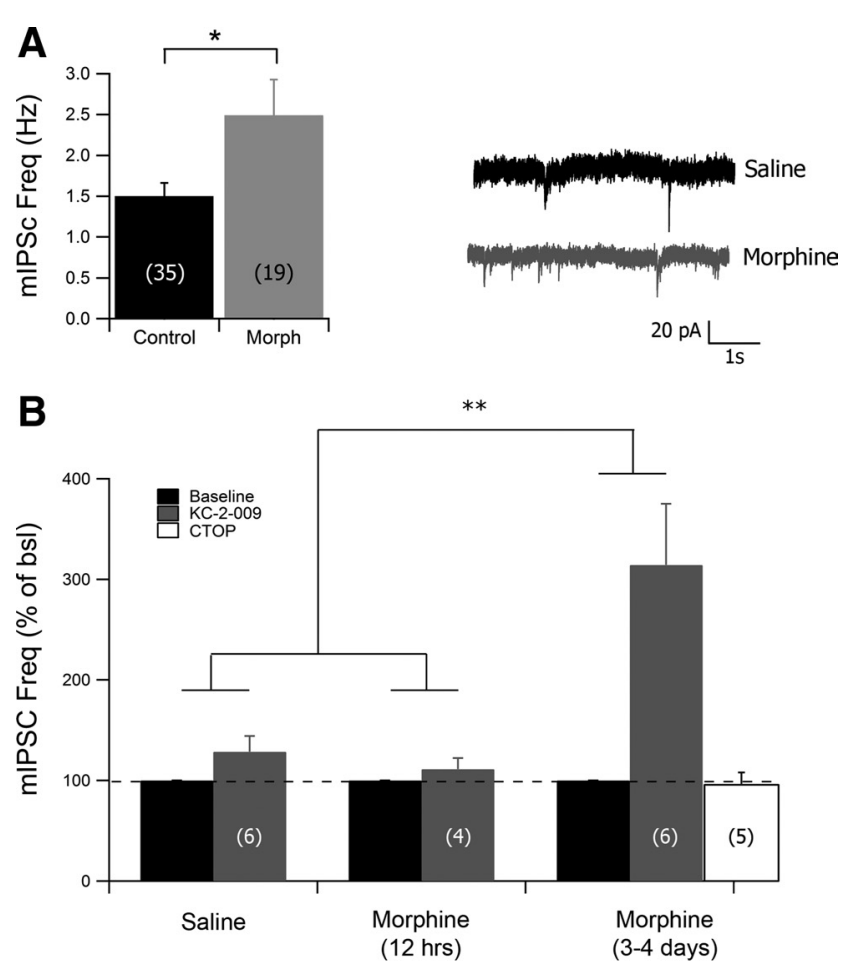

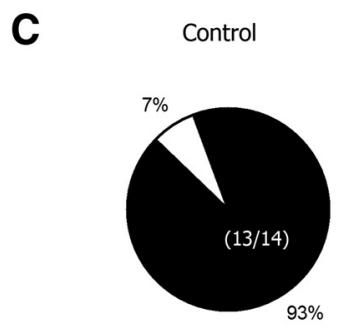

DAMGO-inhibition
A
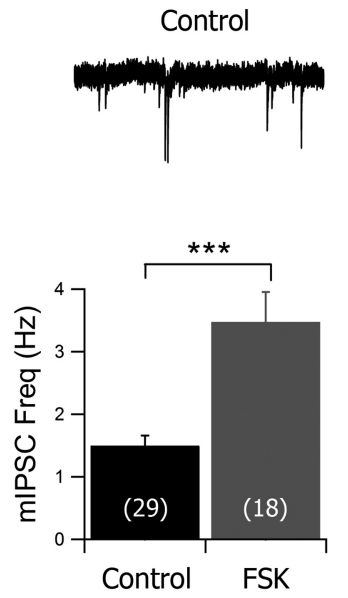

B

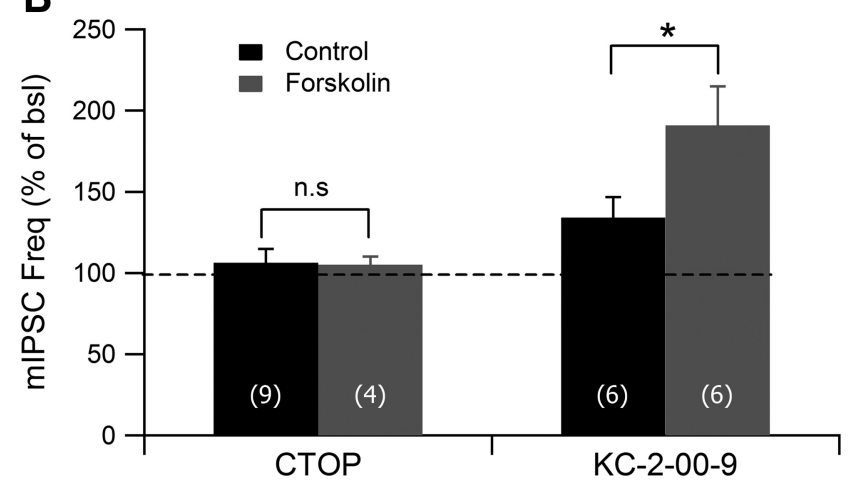

Figure 5. Pretreatment with adenylate cyclase activator FSK is sufficient to enhance MOR constitutive activity in the VTA. $A$, Top, Representative mIPSC traces in the absence and presence of $0.1 \mu \mathrm{M}$ FSK. Bottom, FSK increased the baseline frequency of mIPSCs onto VTA dopamine neurons compared with control. $\boldsymbol{B}$, Differential effects of the MOR neutral antagonist CTOP and the inverse agonist KC-2-009 in the absence and presence of FSK. Percentage change is with respect to the stabilized FSK-containing baseline. FSK pretreatment enhanced the effect of KC-2-009, whereas it did not change the effect of CTOP. Number of experiments indicated in parentheses. ${ }^{*} p<0.05$; ${ }^{* * *} p<0.001$.

Figure 4. Morphine withdrawal enhances MOR constitutive activity in the VTA. $\boldsymbol{A}$, Morphine withdrawal increased the baseline frequency of mIPSCs onto VTA dopamine neurons compared with control. $\boldsymbol{B}$, The MOR inverse agonist KC-2-009 (1 $\mu \mathrm{m})$ led to a greater increase in mIPSC frequency after 3-4 d of withdrawal from chronic morphine, compared with either saline treatment or only $12 \mathrm{~h}$ of morphine abstinence. The MOR neutral antagonist CTOP was still without effect after 3-4 d of withdrawal, suggesting there was no increased release of endogenous opioids in the slice preparation. Note that effects are with respect to the baseline of the cell, correcting for any effects of morphine withdrawal on baseline frequency itself. $\boldsymbol{C}$, Percentage of VTA dopamine neurons suppressed by the MOR agonist DAMGO during control conditions (left) or after morphine withdrawal (right). After morphine withdrawal, DAMGO only reduced $\mathrm{mIPSC}$ frequency in a minority of cells. The number of experiments is indicated in parentheses. ${ }^{*} p<0.05 ;{ }^{* *} p<0.01$.

is also the case during morphine withdrawal. Moreover, this aspect of morphine withdrawal is sufficient to increase MOR constitutive activity in the VTA.

\section{Discussion}

MOR signaling in the VTA plays an important role in reward processing and aspects of addiction (Bozarth and Wise, 1984; Wise, 1989; Laviolette et al., 2004), including opiate withdrawal (Bonci and Williams, 1997; Madhavan et al., 2010a). We now show inverse agonistic effects at the MOR in the VTA, likely suggesting a role for constitutive agonist-independent MOR activation in the regulation of GABAergic control of VTA dopamine neurons. Furthermore, such MOR constitutive activity is especially prominent during morphine withdrawal.
The MOR-dependent inverse agonism by $\mathrm{KC}-2-009$ on mIPSC frequency in the VTA is most likely best explained by suppression of constitutive MOR activity. Indeed, the effect of KC-2-009 was reliably blocked by the selective MOR neutral antagonist CTOP. While KC-2-009 also has low affinity for the KOR (Sally et al., 2010), its inverse agonistic effect was not blocked by the selective KOR antagonist Nor-BNI. Moreover, the effect of KC-2-009 was not due to interference with endogenous opioid signaling, since CTOP had no effect on mIPSC frequency itself. Finally, pretreatment with KC-2-009 blocked the effect of DAMGO, suggesting they act on a similar target (i.e., the MOR). Together these data suggest that a population of MORs in the VTA is constitutively active and involved in regulating inhibitory GABAergic transmission onto dopamine neurons in the VTA. This finding is in accordance with the report that inverse agonistic effects at the MOR occur at the level of G-protein binding and adenylate cyclase activity in morphine-exposed mouse brain homogenates, including punches of the midbrain, but not in MOR knock-out animals (Wang et al., 2004). Such findings suggest that constitutively active MORs and agonist-activated MORs may share much of the same downstream signaling cascade. However, there is also evidence that different active conformations of the MOR exist, with their own associated downstream signaling characteristics ( $\mathrm{Xu}$ et al., 2008). Therefore, future experiments 
need to validate whether or not the pathway used by constitutively active MORs in regions like the VTA is similar to that of, for instance, DAMGO-activated MORs.

The physiological occurrence of MOR constitutive activity is highly relevant for certain aspects of drug addiction. It has been proposed that MORs become increasingly constitutively active during morphine withdrawal as an adaptation to the sudden lack of morphine that the system has grown accustomed to (Wang et al., 1994). Such enhanced MOR constitutive activity can last for more days when the exposure to opiates has been greater (Wang et al., 2004). We indeed observed that after 3-4 d of withdrawal from chronic morphine treatment, the effect of the MOR inverse agonist KC-2-009 on GABAergic inputs to VTA dopamine neurons was strongly enhanced. Such enhancement of inverse agonistic effects at the MOR after withdrawal from a MOR agonist also occurs in artificial cell systems and in brain homogenates (Wang et al., 2004; Raehal et al., 2005). Interestingly, we did not observe a pronounced increase in the efficacy of KC-2-009 after only $12 \mathrm{~h}$ abstinence from morphine. This suggests that the changes in MOR constitutive activity are not a direct response to the chronic administration of morphine itself, but become pronounced later in the withdrawal period. We also observed that the effect of the MOR agonist DAMGO was diminished during morphine withdrawal, as has been reported previously (Madhavan et al., 2010b). This suggests a withdrawal-induced shift toward more constitutively active MORs, allowing for less additional agonist-induced activation. Therefore, enhanced MOR constitutive activity may also contribute to the opiate tolerance that develops after chronic use (Christie, 2008). Since our finding suggests that enhanced MOR activity by an agonist can increase MOR constitutive activity, we cannot entirely rule out the possibility that the magnitude of constitutive MOR activity in our slice preparation was relatively heightened by the release of opiates during euthanasia. However, it is important to note that strong evidence suggests that MOR constitutive activity also occurs in freely moving animals (Wang et al., 1994; Bilsky et al., 1996; Raehal et al., 2005; Shoblock and Maidment, 2006), supporting its physiological relevance.

A critical component of morphine withdrawal is the occurrence of cAMP superactivation, which is likely responsible for the negative withdrawal state (Terwilliger et al., 1991; Bonci and Williams, 1997; Madhavan et al., 2010a). This cAMP increase may in itself trigger adaptive counteractive processes, like enhanced MOR constitutive signaling, to suppress cAMP (Wang et al., 1994, 2001, 2004; Liu and Prather, 2001). Indeed, cAMPdependent kinases have been reported to increase MOR phosphorylation, thereby elevating constitutive activity (Wang et al., 1994; Bilsky et al., 1996). In accordance with such findings in artificial cell systems, we now show that acute treatment with FSK to activate the cAMP-pathway is sufficient to enhance inverse agonistic effects at the MOR in the VTA. The exact molecular cascade of events through which enhanced adenylate cyclase activity elevates MOR constitutive activity requires further elucidation. It also remains to be determined whether continued elevation of cAMP levels is required for the enhanced MOR constitutive activity, or whether the changes in MOR constitutive activity represent a sequential step that can even outlast the changes in cAMP levels.

The opioid antagonists naloxone and naltrexone are currently commonly prescribed to treat opiate overdose and addiction. However, these ligands act like MOR inverse agonists in systems previously exposed to opioids, and can produce serious adverse effects (Sadée et al., 2005). There are strong indications that a hypofunctional dopamine system stands at the root of many of these negative effects (Baumeister et al., 1989; Koob and Le Moal, 1997, 2001; Aston-Jones and Harris, 2004; Madhavan et al., 2010a; Radke et al., 2011). Our findings confirm previous reports that during morphine withdrawal, GABAergic signaling onto VTA dopamine neurons is enhanced (Bonci and Williams, 1997; Madhavan et al., 2010a). This is likely an important contributor to the hypofunctionality of VTA dopamine neurons during morphine withdrawal. Notably, morphine withdrawal is also associated with alterations in the nucleus accumbens (NAc) shell, a prominent target region of the VTA. Extended $(10 \mathrm{~d})$ but not acute $(12 \mathrm{~h})$ withdrawal from a similar morphine treatment schedule was found to enhance both the excitability of medium spiny neurons (MSNs), as well as their glutamatergic input ( $\mathrm{Wu}$ et al., 2012). Interestingly, in another study, morphine withdrawal was linked to enhanced c-Fos expression specifically in MSNs in the NAc that express the dopamine 2 (D2), rather than the dopamine 1 (D1) receptor (Enoksson et al., 2012). Since dopamine signaling oppositely affects excitability of D2 receptor MSNs and D1 receptor MSNs (Neve et al., 2004; Surmeier et al., 2007), morphine withdrawal-induced VTA hypofunctionality (Acquas et al., 1991; Diana et al., 1995, 1999; Koob and Le Moal, 1997, 2001; Aston-Jones and Harris, 2004; Radke et al., 2011) would likely shift the balance in the NAc toward more activation of D2-receptor MSNs. Whereas striatal activation of D1-receptor MSNs seems to underlie rewarding processes, activation of striatal D2-receptor MSNs appears to be more linked to antireward or aversive processes (Lobo et al., 2010; Enoksson et al., 2012; Kravitz et al., 2012; Pascoli et al., 2012). Interference with constitutively active MORs on GABAergic terminals to VTA dopamine neurons would be expected to even further diminish dopamine signaling in regions like the NAc shell, leading to a further shift toward activity in D2-receptor MSNs, a potential correlate for the expression of adverse symptoms. Indeed, enhancing dopamine signaling in the NAc shell ameliorates anxiety-like symptoms caused by morphine withdrawal (Radke and Gewirtz, 2012). Despite the importance of this particular VTA projection to the NAc shell, it is clear that morphine withdrawal is a multifacetted state to which many other brain regions also contribute, including for instance the amygdala and periaquaductal gray (Maldonado et al., 1992; Gracy et al., 2001; Williams et al., 2001). Interestingly, MORs serve important regulatory functions in such regions as well (Williams et al., 2001; Contet et al., 2004). This opens up the possibility that constitutively active MORs in these regions also serve an important role in morphine withdrawal that may be affected by MOR inverse agonists.

Although MOR neutral antagonists and inverse agonists can both produce opiate withdrawal effects (e.g., jumping, tremors, and place aversion), there is now strong evidence that neutral MOR antagonists do so to a lesser extent than inverse agonists (Wang et al., 1994; Bilsky et al., 1996; Raehal et al., 2005; Shoblock and Maidment, 2006). MOR neutral antagonists therefore have the potential to be safer therapeutic agents to treat both opiate addiction and overdose. These reports connect well with our current findings that MOR constitutive activity regulates GABAergic signaling in a key brain region involved in opioid withdrawal (Baumeister et al., 1989; Koob and Le Moal, 1997, 2001; AstonJones and Harris, 2004; Radke et al., 2011).

\section{References}

Acquas E, Carboni E, Di Chiara G (1991) Profound depression of mesolimbic dopamine release after morphine withdrawal in dependent rats. Eur J Pharmacol 193:133-134.

Aston-Jones G, Harris GC (2004) Brain substrates for increased drug seek- 
ing during protracted withdrawal. Neuropharmacology 47 [Suppl 1]: 167-179.

Bagley EE, Hacker J, Chefer VI, Mallet C, McNally GP, Chieng BC, Perroud J, Shippenberg TS, Christie MJ (2011) Drug-induced GABA transporter currents enhance GABA release to induce opioid withdrawal behaviors. Nat Neurosci 14:1548-1554.

Baumeister AA, Anticich TG, Hebert G, Hawkins MF, Nagy M (1989) Evidence that physical dependence on morphine is mediated by the ventral midbrain. Neuropharmacology 28:1151-1157.

Bergevin A, Girardot D, Bourque MJ, Trudeau LE (2002) Presynaptic muopioid receptors regulate a late step of the secretory process in rat ventral tegmental area GABAergic neurons. Neuropharmacology 42:1065-1078.

Bilsky EJ, Bernstein RN, Wang Z, Sadée W, Porreca F (1996) Effects of naloxone and D-Phe-Cys-Tyr-D-Trp-Arg-Thr-Pen-Thr-NH2 and the protein kinase inhibitors $\mathrm{H} 7$ and $\mathrm{H} 8$ on acute morphine dependence and antinociceptive tolerance in mice. J Pharmacol Exp Ther 277:484-490.

Bonci A, Williams JT (1997) Increased probability of GABA release during withdrawal from morphine. J Neurosci 17:796-803.

Bozarth MA, Wise RA (1984) Anatomically distinct opiate receptor fields mediate reward and physical dependence. Science 224:516-517.

Brussaard AB, Kits KS, de Vlieger TA (1996) Postsynaptic mechanism of depression of GABAergic synapses by oxytocin in the supraoptic nucleus of immature rat. J Physiol 497:495-507.

Burford NT, Wang D, Sadée W (2000) G-protein coupling of mu-opioid receptors (OP3): elevated basal signalling activity. Biochem J 348:531537.

Cadet P, Mantione KJ, Stefano GB (2003) Molecular identification and functional expression of mu 3 , a novel alternatively spliced variant of the human mu opiate receptor gene. J Immunol 170:5118-5123.

Christie MJ (2008) Cellular neuroadaptations to chronic opioids: tolerance, withdrawal and addiction. Br J Pharmacol 154:384-396.

Contet C, Kieffer BL, Befort K (2004) Mu opioid receptor: a gateway to drug addiction. Curr Opin Neurobiol 14:370-378.

de Rover M, Meye FJ, Ramakers GM (2008) Presynaptic metabotropic glutamate receptors regulate glutamatergic input to dopamine neurons in the ventral tegmental area. Neuroscience 154:1318-1323.

Diana M, Pistis M, Muntoni A, Gessa G (1995) Profound decrease of mesolimbic dopaminergic neuronal activity in morphine withdrawn rats. J Pharmacol Exp Ther 272:781-785.

Diana M, Muntoni AL, Pistis M, Melis M, Gessa GL (1999) Lasting reduction in mesolimbic dopamine neuronal activity after morphine withdrawal. Eur J Neurosci 11:1037-1041.

Enoksson T, Bertran-Gonzalez J, Christie MJ (2012) Nucleus accumbens D2- and D1-receptor expressing medium spiny neurons are selectively activated by morphine withdrawal and acute morphine, respectively. Neuropharmacology 62:2463-2471.

Fields HL, Hjelmstad GO, Margolis EB, Nicola SM (2007) Ventral tegmental area neurons in learned appetitive behavior and positive reinforcement. Annu Rev Neurosci 30:289-316.

Garzón M, Pickel VM (2001) Plasmalemmal mu-opioid receptor distribution mainly in nondopaminergic neurons in the rat ventral tegmental area. Synapse 41:311-328.

Ghozland S, Matthes HW, Simonin F, Filliol D, Kieffer BL, Maldonado R (2002) Motivational effects of cannabinoids are mediated by $\mu$-opioid and $\kappa$-opioid receptors. J Neurosci 22:1146-1154.

Gracy KN, Dankiewicz LA, Koob GF (2001) Opiate withdrawal-induced fos immunoreactivity in the rat extended amygdala parallels the development of conditioned place aversion. Neuropsychopharmacology 24:152-160.

Hall FS, Sora I, Uhl GR (2001) Ethanol consumption and reward are decreased in mu-opiate receptor knockout mice. Psychopharmacology (Berl) 154:43-49.

Heinzen EL, Booth RG, Pollack GM (2005) Neuronal nitric oxide modulates morphine antinociceptive tolerance by enhancing constitutive activity of the mu-opioid receptor. Biochem Pharmacol 69:679-688.

Jalabert M, Bourdy R, Courtin J, Veinante P, Manzoni OJ, Barrot M, Georges F (2011) Neuronal circuits underlying acute morphine action on dopamine neurons. Proc Natl Acad Sci U S A 108:16446-16450.

Jarjour S, Bai L, Gianoulakis C (2009) Effect of acute ethanol administration on the release of opioid peptides from the midbrain including the ventral tegmental area. Alcohol Clin Exp Res 33:1033-1043.

Johnson SW, North RA (1992) Opioids excite dopamine neurons by hyperpolarization of local interneurons. J Neurosci 12:483-488.
Koob GF, Le Moal M (1997) Drug abuse: hedonic homeostatic dysregulation. Science 278:52-58.

Koob GF, Le Moal M (2001) Drug addiction, dysregulation of reward, and allostasis. Neuropsychopharmacology 24:97-129.

Kravitz AV, Tye LD, Kreitzer AC (2012) Distinct roles for direct and indirect pathway striatal neurons in reinforcement. Nat Neurosci 15:816-818.

Labouèbe G, Lomazzi M, Cruz HG, Creton C, Luján R, Li M, Yanagawa Y, Obata K, Watanabe M, Wickman K, Boyer SB, Slesinger PA, Lüscher C (2007) RGS2 modulates coupling between GABAB receptors and GIRK channels in dopamine neurons of the ventral tegmental area. Nat Neurosci 10:1559-1568.

Lam H, Maga M, Pradhan A, Evans CJ, Maidment NT, Hales TG, Walwyn W (2011) Analgesic tone conferred by constitutively active mu opioid receptors in mice lacking beta-arrestin 2. Mol Pain 7:24.

Laviolette SR, Gallegos RA, Henriksen SJ, van der Kooy D (2004) Opiate state controls bidirectional reward signaling via GABAA receptors in the ventral tegmental area. Nat Neurosci 7:160-169.

Liu JG, Prather PL (2001) Chronic exposure to mu-opioid agonists produces constitutive activation of mu-opioid receptors in direct proportion to the efficacy of the agonist used for pretreatment. Mol Pharmacol 60:53-62.

Liu JG, Ruckle MB, Prather PL (2001) Constitutively active mu-opioid receptors inhibit adenylyl cyclase activity in intact cells and activate G-proteins differently than the agonist [D-Ala2,N-MePhe4,Glyol5] enkephalin. J Biol Chem 276:37779-37786.

Lobo MK, Covington HE 3rd, Chaudhury D, Friedman AK, Sun H, DamezWerno D, Dietz DM, Zaman S, Koo JW, Kennedy PJ, Mouzon E, Mogri M, Neve RL, Deisseroth K, Han MH, Nestler EJ (2010) Cell type-specific loss of BDNF signaling mimics optogenetic control of cocaine reward. Science 330:385-390.

Madhavan A, He L, Stuber GD, Bonci A, Whistler JL (2010a) micro-Opioid receptor endocytosis prevents adaptations in ventral tegmental area GABA transmission induced during naloxone-precipitated morphine withdrawal. J Neurosci 30:3276-3286.

Madhavan A, Bonci A, Whistler JL (2010b) Opioid-Induced GABA potentiation after chronic morphine attenuates the rewarding effects of opioids in the ventral tegmental area. J Neurosci 30:14029-14035.

Maldonado R, Stinus L, Gold LH, Koob GF (1992) Role of different brain structures in the expression of the physical morphine withdrawal syndrome. J Pharmacol Exp Ther 261:669-677.

Mameli M, Halbout B, Creton C, Engblom D, Parkitna JR, Spanagel R, Lüscher C (2009) Cocaine-evoked synaptic plasticity: persistence in the VTA triggers adaptations in the NAc. Nat Neurosci 12:1036-1041.

Manzoni OJ, Williams JT (1999) Presynaptic regulation of glutamate release in the ventral tegmental area during morphine withdrawal. J Neurosci 19:6629-6636.

Mathon DS, Kamal A, Smidt MP, Ramakers GM (2003) Modulation of cellular activity and synaptic transmission in the ventral tegmental area. Eur J Pharmacol 480:97-115.

Mathon DS, Lesscher HM, Gerrits MA, Kamal A, Pintar JE, Schuller AG, Spruijt BM, Burbach JP, Smidt MP, van Ree JM, Ramakers GM (2005) Increased gabaergic input to ventral tegmental area dopaminergic neurons associated with decreased cocaine reinforcement in mu-opioid receptor knockout mice. Neuroscience 130:359-367.

Matsui A, Williams JT (2011) Opioid-sensitive GABA inputs from rostromedial tegmental nucleus synapse onto midbrain dopamine neurons. J Neurosci 31:17729-17735.

Matthes HW, Maldonado R, Simonin F, Valverde O, Slowe S, Kitchen I, Befort K, Dierich A, Le Meur M, Doll é P, Tzavara E, Hanoune J, Roques BP, Kieffer BL (1996) Loss of morphine-induced analgesia, reward effect and withdrawal symptoms in mice lacking the mu-opioid-receptor gene. Nature 383:819-823.

Mitchell JM, O’Neil JP, Janabi M, Marks SM, Jagust WJ, Fields HL (2012) Alcohol consumption induces endogenous opioid release in the human orbitofrontal cortex and nucleus accumbens. Sci Transl Med 4: 116 ra6.

Neuhoff H, Neu A, Liss B, Roeper J (2002) $I_{\mathrm{h}}$ channels contribute to the different functional properties of identified dopaminergic subpopulations in the midbrain. J Neurosci 22:1290-1302.

Neve KA, Seamans JK, Trantham-Davidson H (2004) Dopamine receptor signaling. J Recept Signal Transduct Res 24:165-205.

Olive MF, Koenig HN, Nannini MA, Hodge CW (2001) Stimulation of en- 
dorphin neurotransmission in the nucleus accumbens by ethanol, cocaine, and amphetamine. J Neurosci 21:RC184.

Padgett CL, Lalive AL, Tan KR, Terunuma M, Munoz MB, Pangalos MN, MartínezHernández J, Watanabe M, Moss SJ, Luján R, Lüscher C, Slesinger PA (2012) Methamphetamine-evoked depression of GABA(B) receptor signaling in GABA neurons of the VTA. Neuron 73:978-989.

Pascoli V, Turiault M, Lüscher C (2012) Reversal of cocaine-evoked synaptic potentiation resets drug-induced adaptive behaviour. Nature 481:71-75.

Radke AK, Gewirtz JC (2012) Increased dopamine receptor activity in the nucleus accumbens shell ameliorates anxiety during drug withdrawal. Neuropsychopharmacology 37:2405-2415.

Radke AK, Rothwell PE, Gewirtz JC (2011) An anatomical basis for opponent process mechanisms of opiate withdrawal. J Neurosci 31:7533-7539.

Raehal KM, Lowery JJ, Bhamidipati CM, Paolino RM, Blair JR, Wang D, Sadée W, Bilsky EJ (2005) In vivo characterization of 6beta-naltrexol, an opioid ligand with less inverse agonist activity compared with naltrexone and naloxone in opioid-dependent mice. J Pharmacol Exp Ther 313:1150-1162.

Roth-Deri I, Zangen A, Aleli M, Goelman RG, Pelled G, Nakash R, GispanHerman I, Green T, Shaham Y, Yadid G (2003) Effect of experimenterdelivered and self-administered cocaine on extracellular beta-endorphin levels in the nucleus accumbens. J Neurochem 84:930-938.

Sadée W, Wang D, Bilsky EJ (2005) Basal opioid receptor activity, neutral antagonists, and therapeutic opportunities. Life Sci 76:1427-1437.

Sally EJ, Xu H, Dersch CM, Hsin LW, Chang LT, Prisinzano TE, Simpson DS, Giuvelis D, Rice KC, Jacobson AE, Cheng K, Bilsky EJ, Rothman RB (2010) Identification of a novel "almost neutral" micro-opioid receptor antagonist in $\mathrm{CHO}$ cells expressing the cloned human mu-opioid receptor. Synapse 64:280-288.

Sharma SK, Klee WA, Nirenberg M (1975) Dual regulation of adenylate cyclase accounts for narcotic dependence and tolerance. Proc Natl Acad Sci U S A 72:3092-3096.

Shoblock JR, Maidment NT (2006) Constitutively active micro opioid receptors mediate the enhanced conditioned aversive effect of naloxone in morphine-dependent mice. Neuropsychopharmacology 31:171-177.

Smidt MP, van Schaick HS, Lanctôt C, Tremblay JJ, Cox JJ, van der Kleij AA, Wolterink G, Drouin J, Burbach JP (1997) A homeodomain gene Ptx3 has highly restricted brain expression in mesencephalic dopaminergic neurons. Proc Natl Acad Sci U S A 94:13305-13310.

Solinas M, Zangen A, Thiriet N, Goldberg SR (2004) Beta-endorphin eleva- tions in the ventral tegmental area regulate the discriminative effects of Delta-9-tetrahydrocannabinol. Eur J Neurosci 19:3183-3192.

Surmeier DJ, Ding J, Day M, Wang Z, Shen W (2007) D1 and D2 dopaminereceptor modulation of striatal glutamatergic signaling in striatal medium spiny neurons. Trends Neurosci 30:228-235.

Takemori AE, Ho BY, Naeseth JS, Portoghese PS (1988) Nor-binaltorphimine, a highly selective kappa-opioid antagonist in analgesic and receptor binding assays. J Pharmacol Exp Ther 246:255-258.

Terwilliger RZ, Beitner-Johnson D, Sevarino KA, Crain SM, Nestler EJ (1991) A general role for adaptations in G-proteins and the cAMP system in mediating the chronic actions of morphine and cocaine on neuronal function. Brain Res 548:100-110.

Walwyn W, Evans CJ, Hales TG (2007) $\beta$-Arrestin2 and c-Src regulate the constitutive activity and recycling of $\mu$ opioid receptors in dorsal root ganglion neurons. J Neurosci 27:5092-5104.

Wang D, Raehal KM, Bilsky EJ, Sadée W (2001) Inverse agonists and neutral antagonists at mu opioid receptor (MOR): possible role of basal receptor signaling in narcotic dependence. J Neurochem 77:1590-1600.

Wang D, Raehal KM, Lin ET, Lowery JJ, Kieffer BL, Bilsky EJ, Sadée W (2004) Basal signaling activity of mu opioid receptor in mouse brain: role in narcotic dependence. J Pharmacol Exp Ther 308:512-520.

Wang Z, Bilsky EJ, Porreca F, Sadée W (1994) Constitutive mu opioid receptor activation as a regulatory mechanism underlying narcotic tolerance and dependence. Life Sci 54:PL339-PL350.

Wang Z, Arden J, Sadée W (1996) Basal phosphorylation of mu opioid receptor is agonist modulated and $\mathrm{Ca}^{2+}$-dependent. FEBS Lett 387:53-57.

Williams JT, Christie MJ, Manzoni O (2001) Cellular and synaptic adaptations mediating opioid dependence. Physiol Rev 81:299-343.

Wise RA (1989) Opiate reward: sites and substrates. Neurosci Biobehav Rev 13:129-133.

Wu X, Shi M, Wei C, Yang M, Liu Y, Liu Z, Zhang X, Ren W (2012) Potentiation of synaptic strength and intrinsic excitability in the nucleus accumbens after 10 ds of morphine withdrawal. J Neurosci Res 90: $1270-1283$

Xu H, Wang X, Partilla JS, Bishop-Mathis K, Benaderet TS, Dersch CM, Simpson DS, Prisinzano TE, Rothman RB (2008) Differential effects of opioid agonists on $\mathrm{G}$ protein expression in $\mathrm{CHO}$ cells expressing cloned human opioid receptors. Brain Res Bull 77:49-54.

Zhao S, Maxwell S, Jimenez-Beristain A, Vives J, Kuehner E, Zhao J, O'Brien C, de Felipe C, Semina E, Li M (2004) Generation of embryonic stem cells and transgenic mice expressing green fluorescence protein in midbrain dopaminergic neurons. Eur J Neurosci 19:1133-1140. 